\title{
HUBUNGAN KEPEMIMPINAN DAN MOTIVASI KERJA DENGAN KINERJA KARYAWAN DI PUSKESMAS BENDA BARU KOTA TANGERANG SELATAN TAHUN 2020
}

\author{
Tri Okta Ratnaningtyas*, Sheila Meitania Utami, Tifani Monika, Nurwulan Adi Ismaya
} STIKes Kharisma Persada, Jalan Pajajaran No.1, Tangerang Selatan (15417), Indonesia

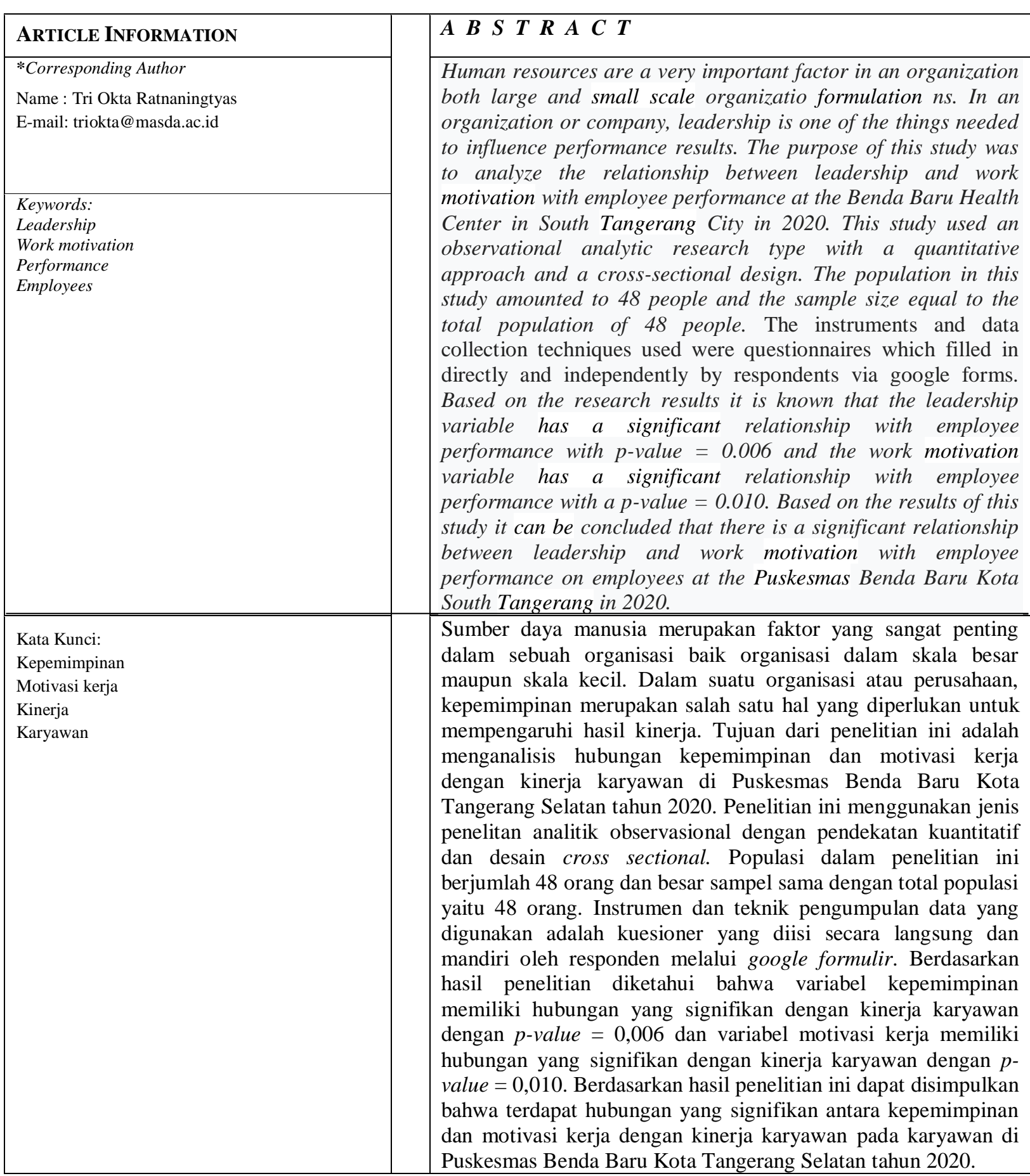




\section{PENDAHULUAN}

Sumber daya manusia merupakan faktor yang sangat penting dalam sebuah organisasi baik organisasi dalam skala besar maupun skala kecil. Suatu instansi didirikan karena memiliki tujuan yang ingin dicapai, sedangkan untuk mencapai tujuan perusahaan membutuhkan sikap atau perilaku orang-orang yang bertanggung jawab dan memiliki kemampuan kinerja yang baik. Menurut Wibowo (2011), kinerja disebut juga dengan performance, ada pula yang memberikan pengertian performance sebagai hasil kerja atau prestasi kerja, namun sebenarnya kinerja mempunyai makna yang lebih luas, bukan hanya hasil kerja, tetapi termasuk bagaimana proses pekerjaan berlangsung.

$$
\text { Variabel yang dapat }
$$

mempengaruhi kinerja pegawai menurut Wirawan (2009) yaitu kepemimpinan dan motivasi kerja pegawai. Dalam suatu organisasi atau perusahaan, kepemimpinan adalah kemampuan untuk mempengaruhi pihak lain, melalui komunikasi baik langsung maupun tidak langsung dengan maksud untuk menggerakkan orang-orang agar dengan penuh pengertian, kesadaran, dan senang hati bersedia mengikuti kehendak pimpinan tersebut (Anoraga, 2008).
Sedangkan, menurut (Wirawan 2009), motivasi kerja merupakan dorongan kepada karyawan untuk melaksanakan pekerjaannya dengan lebih baik.

Menurut penelitian yang dilakukan oleh Dwi Wahyu Wijayanti (2012), diketahui bahwa kepemimpinan sangat berpengaruh terhadap kinerja karyawan dan sejalan dengan motivasi kerja juga sangat berpengaruh terhadap kinerja karyawan. Faktor yang berpengaruh untuk mencapai hasil kinerja yang baik dari karyawan adalah kemampuan pemimpin yang bersikap mendukung dan mewujudkan simpati pada karyawan atau bawahannya sehingga bisa mencapai kinerja yang baik agar tujuan perusahaan dapat tercapai (Inaray, 2016). Berdasarkan uraian di atas maka peneliti tertarik untuk menganalisis hubungan kepemimpinan dan motivasi kerja dengan kinerja karyawan di Puskesamas Benda Baru Kota Tangerang Selatan Tahun 2020.

\section{METODE}

Penelitian ini menggunakan jenis penelitan analitik observasional dengan pendekatan kuantitatif dan desain cross sectional. Populasi dalam penelitian ini berjumlah 48 orang dan besar sampel sama dengan total populasi yaitu 48 
orang. Teknik pengambilan sampel yang digunakan dalam penelitian ini adalah teknik sampel jenuh. Instrumen dan teknik pengumpulan data yang digunakan adalah kuesioner yang diisi secara

\section{HASIL PENELITIAN}

\section{Hasil Analisis Univariat}

Karakteristik responden dalam penelitian ini dibedakan atas usia, jenis kelamin, dan pendidikan langsung dan mandiri oleh responden melalui google formulir. Analisis data yang digunakan dalam penelitian ini adalah uji hubungan yaitu uji Chi Square.

Tabel 1. Distribusi Frekuensi Karakteristik Responden Berdasarkan Usia, Jenis Kelamin, dan Pendidikan

\begin{tabular}{|c|c|c|c|}
\hline No. & $\begin{array}{c}\text { Karakteristik } \\
\text { Responden }\end{array}$ & $\begin{array}{c}\text { Jumlah } \\
\text { (n) }\end{array}$ & $\begin{array}{c}\text { Persentase } \\
(\%)\end{array}$ \\
\hline \multicolumn{4}{|c|}{ Usia } \\
\hline & a. 24-30 tahun & 13 & 27,1 \\
\hline & b. 31-37 tahun & 16 & 33,3 \\
\hline & c. $38-44$ tahun & 11 & 22,9 \\
\hline & d. 45-51 tahun & 8 & 16,7 \\
\hline \multicolumn{2}{|r|}{ Total } & 48 & 100,0 \\
\hline \multirow[t]{3}{*}{2.} & Jenis Kelamin & & \\
\hline & a. Laki-Laki & 12 & 25,0 \\
\hline & b. Perempuan & 36 & 75,0 \\
\hline \multicolumn{2}{|r|}{ Total } & 48 & 100,0 \\
\hline \multirow[t]{4}{*}{3.} & Pendidikan & & \\
\hline & a. SMA & 15 & 31,3 \\
\hline & b. D3 s.d. S3 & 33 & 68,7 \\
\hline & Total & 48 & 100,0 \\
\hline
\end{tabular}

Sumber: Data Primer (2020)

Berdasarkan distribusi frekuensi karakteristik responden yang telah dijelaskan dalam tabel 1 diketahui usia dari sebagian besar responden adalah berkisar 31 sampai 37 tahun sebanyak 16 responden dengan persentase $33,3 \%$, jenis

\section{a. Karakteristik Responden}

sebagaimana dijelaskan pada tabel berikut: 
responden dengan persentase 68,7\%.

\section{b. Kepemimpinan}

Faktor kepemimpinan pada

wakil organisasi, kepemimpinan

penelitian ini meliputi bersifat

adil, memberikan sugesti,

sebagai sumber inspirasi, dan

mendukung tercapainya tujuan,

kepemimpinan

bersikap

katalisator, menciptakan rasa

menghargai

sebagaimana

aman, kepemimpinan sebagai

Tabel 2. Distribusi Frekuensi Kepemimpinan Berdasarkan Indikator Kepemimpinan yaitu Bersifat Adil, Memberikan Sugesti, Mendukung Tercapainya Tujuan,

Katalisator, Menciptakan Rasa Aman, Kepemimpinan sebagai Wakil

Organisasi, Kepemimpinan sebagai Sumber Inspirasi, dan

Kepemimpinan Bersikap Menghargai

\begin{tabular}{|c|c|c|c|}
\hline No. & Kepemimpinan & Jumlah (n) & Persentase (\%) \\
\hline 1. & $\begin{array}{l}\text { Bersifat Adil } \\
\text { a. Baik } \\
\text { b. Tidak Baik }\end{array}$ & $\begin{array}{c}45 \\
3\end{array}$ & $\begin{array}{c}93,8 \\
6,2\end{array}$ \\
\hline & Total & 48 & 100,0 \\
\hline 2. & $\begin{array}{l}\text { Memberikan Sugesti } \\
\text { a. Baik } \\
\text { b. Tidak Baik }\end{array}$ & $\begin{array}{c}45 \\
3\end{array}$ & $\begin{array}{c}93,8 \\
6,2\end{array}$ \\
\hline & Total & 48 & 100,0 \\
\hline 3. & $\begin{array}{l}\text { Mendukung } \\
\text { Tercapainya Tujuan } \\
\text { a. Baik } \\
\text { b. Tidak Baik }\end{array}$ & $\begin{array}{c}43 \\
5\end{array}$ & $\begin{array}{l}89,6 \\
10,4\end{array}$ \\
\hline & Total & 48 & 100,0 \\
\hline 4. & $\begin{array}{l}\text { Katalisator } \\
\text { a. Baik } \\
\text { b. Tidak Baik }\end{array}$ & $\begin{array}{c}42 \\
6\end{array}$ & $\begin{array}{l}87,5 \\
12,5\end{array}$ \\
\hline & Total & 48 & 100,0 \\
\hline 5. & $\begin{array}{l}\text { Menciptakan Rasa } \\
\text { Aman } \\
\text { a. Baik } \\
\text { b. Tidak Baik }\end{array}$ & $\begin{array}{c}43 \\
5\end{array}$ & $\begin{array}{l}89,6 \\
10,4\end{array}$ \\
\hline & Total & 48 & 100,0 \\
\hline 6. & $\begin{array}{l}\text { Kepemimpinan sebagai } \\
\text { Wakil Organisasi } \\
\text { a. Baik } \\
\text { b. Tidak Baik }\end{array}$ & $\begin{array}{c}42 \\
6\end{array}$ & $\begin{array}{l}87,5 \\
12,5\end{array}$ \\
\hline & Total & 48 & 100,0 \\
\hline 7. & $\begin{array}{l}\text { Kepemimpinan sebagai } \\
\text { Sumber Inspirasi } \\
\text { a. Baik } \\
\text { b. Tidak Baik }\end{array}$ & $\begin{array}{c}44 \\
4\end{array}$ & $\begin{array}{c}91,7 \\
8,3\end{array}$ \\
\hline & Total & 48 & 100,0 \\
\hline
\end{tabular}




\begin{tabular}{clcc}
\hline No. & \multicolumn{1}{c}{ Kepemimpinan } & Jumlah (n) & Persentase (\%) \\
\hline 8. & Kepemimpinan & & \\
& Bersikap Menghargai & & \\
& a. Baik & 44 & 91,7 \\
b. Tidak Baik & 4 & 8,3 \\
\hline & Total & $\mathbf{4 8}$ & $\mathbf{1 0 0 , 0}$ \\
\hline
\end{tabular}

Sumber: Data Primer (2020)

Berdasarkan tabel 2 diketahui

bahwa hampir seluruh responden menilai kepemimpinan baik berdasakan indikator bersifat adil yaitu sebesar 45 responden $(93,8 \%) ; \quad$ hampir seluruh responden menilai kepemimpinan baik berdasarkan indikator memberikan sugesti yaitu sebesar 45 responden (93,8\%); hampir seluruh responden menilai kepemimpinan baik berdasakan indikator mendukung tercapainya tujuan yaitu sebesar 43 responden $(89,6 \%)$; hampir seluruh responden menilai kepemimpinan baik berdasarkan indikator katalisator yaitu sebesar 42 responden $(87,5 \%)$; hampir seluruh responden menilai Dalam penelitian ini, variabel motivasi kerja meliputi hubungan dengan rekan kerja dan atasan, lingkungan kerja, kesempatan kepemimpinan baik berdasarkan indikator menciptakan rasa aman yaitu sebesar 43 responden $(89,6 \%)$; hampir seluruh responden menilai kepemimpinan baik berdasarkan indikator kepemimpinan sebagai wakil organisasi yaitu sebesar 42 responden $(87,5 \%)$; hampir seluruh responden menilai kepemimpinan baik berdasarkan indikator kepemimpinan sebagai sumber inspirasi yaitu sebesar 44 responden (91,7\%); dan hampir seluruh responden menilai kepemimpinan baik berdasarkan indikator kepemimpinan bersikap menghargai yaitu sebesar 44 responden $(91,7 \%)$.

\section{c. Motivasi Kerja}

meningkatkan pengetahuan dan keterampilan, dan pemberian tunjangan sebagaimana dijelaskan pada tabel 3: 
Tabel 3. Distribusi Frekuensi Motivasi Kerja Berdasarkan Hubungan dengan Rekan Kerja dan Atasan, Lingkungan Kerja, Kesempatan Meningkatkan Pengetahuan dan

Keterampilan, dan Pemberian Tunjangan

\begin{tabular}{|c|c|c|c|}
\hline No. & Motivasi Kerja & $\begin{array}{c}\text { Jumlah } \\
\text { (n) }\end{array}$ & $\begin{array}{c}\text { Persentase } \\
(\%)\end{array}$ \\
\hline \multirow[t]{6}{*}{1.} & Hubungan dengan & & \\
\hline & Rekan Kerja dan & & \\
\hline & Atasan & & \\
\hline & a. Baik & 45 & 93,8 \\
\hline & b. Tidak Baik & 3 & 6,2 \\
\hline & Total & 48 & 100,0 \\
\hline \multirow[t]{4}{*}{2.} & Lingkungan Kerja & & \\
\hline & a. Baik & 47 & 97,9 \\
\hline & b. Tidak Baik & 1 & 2,1 \\
\hline & Total & 48 & 100,0 \\
\hline \multirow[t]{7}{*}{3.} & Kesempatan & & \\
\hline & Meningkatkan & & \\
\hline & Pengetahuan dan & & \\
\hline & Keterampilan & & \\
\hline & a. Baik & $\begin{array}{c}47 \\
1\end{array}$ & $\begin{array}{c}97,9 \\
2,1\end{array}$ \\
\hline & b. Tidak Baik & 1 & \\
\hline & Total & 48 & 100,0 \\
\hline \multirow[t]{4}{*}{4.} & Pemberian Tunjangan & & \\
\hline & a. Baik & 47 & 97,9 \\
\hline & b. Tidak Baik & 1 & 2,1 \\
\hline & Total & 48 & 100,0 \\
\hline
\end{tabular}

Sumber: Data Primer (2020)

Berdasarkan distribusi frekuensi motivasi kerja yang telah dijelaskan dalam tabel 3 diketahui bahwa hampir seluruh responden menilai baik tentang motivasi kerja berdasarkan hubungan dengan rekan kerja dan atasan yaitu sebesar 45 responden $(93,8 \%) ; \quad$ hampir seluruh responden menilai baik tentang motivasi kerja berdasarkan lingkungan kerja yaitu sebesar 47 Dalam penelitian ini, variabel kinerja meliputi kuantitas, responden $(97,9 \%)$ hampir seluruh responden menilai baik tentang motivasi kerja berdasarkan kesempatan meningkatkan pengetahuan dan keterampilan yaitu sebesar 47 responden $(97,9 \%)$; dan hampir seluruh responden menilai baik tentang motivasi kerja berdasarkan pemberian tunjangan yaitu sebesar 47 responden $(97,9 \%)$.

\section{d. Kinerja}

kualitas, ketepatan waktu, kehadiran, dan kemampuan 
bekerja sama sebagaimana dijelaskan pada tabel di bawah ini:

Tabel 4. Distribusi Frekuensi Kinerja Berdasarkan Kuantitas, Kualitas, Ketepatan Waktu, Kehadiran, dan Kemampuan Bekerja Sama

\begin{tabular}{|c|c|c|c|}
\hline No. & Kinerja & $\begin{array}{c}\text { Jumlah } \\
\text { (n) }\end{array}$ & $\begin{array}{c}\text { Persentase } \\
(\%)\end{array}$ \\
\hline \multirow[t]{4}{*}{1.} & Kuantitas & & \\
\hline & a. Baik & 47 & 97,9 \\
\hline & b. Tidak Baik & 1 & 2,1 \\
\hline & Total & 48 & 100,0 \\
\hline \multirow[t]{4}{*}{2.} & Kualitas & & \\
\hline & a. Baik & 47 & 97,9 \\
\hline & b. Tidak Baik & 1 & 2,1 \\
\hline & Total & 48 & 100,0 \\
\hline \multirow[t]{4}{*}{3.} & Ketepatan Waktu & & \\
\hline & a. Baik & 45 & 93,8 \\
\hline & b. Tidak Baik & 3 & 6,2 \\
\hline & Total & 48 & 100,0 \\
\hline \multirow[t]{4}{*}{4.} & Kehadiran & & \\
\hline & a. Baik & 43 & 89,6 \\
\hline & b. Tidak Baik & 5 & 10,4 \\
\hline & Total & 48 & 100,0 \\
\hline \multirow[t]{5}{*}{5.} & Kemampuan Bekerja & & \\
\hline & Sama & & \\
\hline & a. Baik & 48 & 100,0 \\
\hline & b. Tidak Baik & 0 & 0,0 \\
\hline & Total & 48 & 100,0 \\
\hline
\end{tabular}

Sumber: Data Primer (2020)

Berdasarkan distribusi frekuensi motivasi kerja yang telah dijelaskan dalam tabel 4 diketahui bahwa hampir seluruh responden menilai baik tentang kinerja berdasarkan kuantitas yaitu sebesar 47 responden $(97,9 \%)$; hampir seluruh responden menilai baik tentang kinerja berdasarkan kualitas yaitu sebesar 47 responden $(97,9 \%)$; hampir seluruh responden menilai baik tentang kinerja berdasarkan ketepatan waktu yaitu sebesar 45 responden $(93,8 \%)$; hampir seluruh responden menilai baik tentang kinerja berdasarkan kehadiran yaitu sebesar 43 responden $(89,6 \%)$; dan seluruh responden menilai baik tentang kinerja berdasarkan kemampuan bekerja sama yaitu sebesar 48 responden $(100,0 \%)$. 


\section{Hasil Analisis Bivariat}

\section{a. Hubungan Kepemimpinan}

\section{dengan Kinerja Karyawan}

Hubungan kepemimpinan dengan

kinerja karyawan dapat dijelaskan

dalam tabel 5 di bawah ini:

Tabel 5. Hasil Analisis Hubungan Kepemimpinan dengan Kinerja Karyawan

\begin{tabular}{|c|c|c|c|c|c|c|c|}
\hline \multirow{3}{*}{ Kepemimpinan } & \multicolumn{4}{|c|}{ Kinerja Karyawan } & \multirow{2}{*}{\multicolumn{2}{|c|}{ Total }} & \multirow{3}{*}{$P$ Value } \\
\hline & \multicolumn{2}{|c|}{ Baik } & \multicolumn{2}{|c|}{ Tidak Baik } & & & \\
\hline & $\mathbf{N}$ & $\%$ & $\mathbf{N}$ & $\%$ & $\mathbf{N}$ & $\%$ & \\
\hline Baik & 26 & 100,0 & 0 & 0,0 & 26 & 100,0 & 0.006 \\
\hline Tidak Baik & 16 & 72,7 & 6 & 27,3 & 22 & 100,0 & 0,000 \\
\hline
\end{tabular}

Sumber: Data Primer (2019)

Berdasarkan tabel 5 diketahui

bahwa seluruh responden yang

menilai kepemimpinan baik

memiliki kinerja yang baik yaitu

sebesar 26 responden $(100,0 \%)$

dan sebagian besar responden

yang menilai kepemimpinan tidak

baik memiliki kinerja baik yaitu

sebesar 16 dari 22 responden

$(72,7 \%)$. Menurut tabel 5 juga

dapat diketahui bahwa

berdasarkan hasil uji statistik

diperoleh $P$ Value sebesar 0,006 dimana nilai tersebut kurang dari $\alpha$ $=0,05$. Hal tersebut menunjukkan ada hubungan yang bermakna antara kepemimpinan dengan kinerja karyawan di Puskesmas Benda Baru Kota Tangerang Selatan.

\section{b. Hubungan Motivasi Kerja} dengan Kinerja Karyawan

Hubungan motivasi kerja dengan kinerja karyawan dapat dijelaskan dalam tabel 6 di bawah ini:

Tabel 6. Hasil Analisis Hubungan Motivasi Kerja dengan Kinerja Karyawan

\begin{tabular}{cccccccc}
\hline \multirow{2}{*}{$\begin{array}{c}\text { Motivasi } \\
\text { Kerja }\end{array}$} & \multicolumn{4}{c}{ Kinerja Karyawan } & \multicolumn{2}{c}{ Total } & \multirow{2}{*}{ P Value } \\
\cline { 2 - 6 } & $\mathbf{N}$ & $\mathbf{\%}$ & $\mathbf{N}$ & $\mathbf{\%}$ & $\mathbf{N}$ & $\boldsymbol{\%}$ & \\
\hline Baik & 40 & 93,0 & 3 & 7,0 & 43 & 100,0 & \multirow{2}{*}{0,010} \\
Tidak Baik & 2 & 40,0 & 3 & 60,0 & 5 & 100,0 & \\
\hline
\end{tabular}

Sumber: Data Primer (2019) 
Berdasarkan tabel 6 diketahui bahwa hampir seluruh responden yang memiliki motivasi kerja baik juga memiliki kinerja yang baik yaitu sebesar 40 responden $(93,0 \%)$ dan sebagian besar responden yang memiliki motivasi kerja tidak baik dengan kinerja yang tidak baik yaitu sebesar 3 responden $(60,0 \%)$. Menurut tabel 6 juga dapat diketahui bahwa berdasarkan hasil uji statistik diperoleh $P$ Value sebesar 0,010 dimana nilai tersebut kurang dari $\alpha$ $=0,05$. Hal tersebut menunjukkan ada hubungan yang bermakna antara motivasi kerja dengan kinerja karyawan di Puskesmas Benda Baru Kota Tangerang Selatan.

\section{PEMBAHASAN}

\section{Hubungan Kepemimpinan dengan} Kinerja Karyawan

Menurut Siagian (2009), kepemimpinan adalah kemampuan seorang untuk mempengaruhi orang lain (dalam hal ini para bawahannya) sehingga orang lain itu mau melakukan kehendak pemimpin meskipun secara pribadi hal itu mungkin tidak disenanginya.
Keberhasilan suatu organisasi sangat tergantung pada mutu kepemimpinan yang terdapat dalam organisasi yang bersangkutan. Oleh karena itu, mutu kepemimpinan yang terdapat dalam suatu organisasi memainkan peranan yang sangat dominan dalam keberhasilan organisasi tersebut melalui kinerja para pegawainya (Siagian, 2002).

Berdasarkan hasil penelitian yang telah dilakukan diketahui bahwa seluruh responden yang menilai kepemimpinan baik memiliki kinerja yang baik yaitu sebesar 26 responden $(100,0 \%)$ dan sebagian besar responden yang menilai kepemimpinan tidak baik memiliki kinerja baik yaitu sebesar 16 dari 22 responden (72,7\%). Selain itu, berdasarkan hasil uji statistik diperoleh $P$ Value sebesar 0,006 dimana nilai tersebut kurang dari $\alpha=$ 0,05 . Hal tersebut menunjukkan ada hubungan yang bermakna antara kepemimpinan dengan kinerja karyawan di Puskesmas Benda Baru Kota Tangerang Selatan.

Hasil penelitian ini sejalan dengan penelitian yang dilakukan oleh Dwi Wahyu Wijayanti (2012) yang menjelaskan bahwa 
kepemimpinan memiliki pengaruh yang positif dan signifikan terhadap kinerja karyawan. Selain itu, hasil penelitian ini juga sejalan dengan penelitan Inez Zaneta Hafizhah (2018) yang menjelaskan bahwa variabel gaya kepemimpinan secara parsial menunjukkan pengaruh signifikan terhadap variabel kinerja pegawai. Kepemimpinan yang baik dalam suatu organisasi akan mempengaruhi atau menghasilkan kinerja karyawan yang baik pula.

\section{Hubungan Motivasi Kerja dengan}

\section{Kinerja Karyawan}

Motivasi adalah dorongan, upaya, dan keinginan yang ada di dalam diri manusia yang mengaktifkan, memberi daya, serta mengarahkan perilaku untuk melaksanakan tugas-tugas dengan baik dalam lingkup pekerjaannya (Hakim dalam Reza, 2010). Berdasarkan pengertian tersebut dapat disimpulkan bahwa motivasi dapat dipandang sebagai fungsi, dalam hal ini motivasi berfungsi sebagai daya penggerak dari dalam individu untuk melakukan aktivitas tertentu guna mencapai tujuan. Menurut Siagian (2002), motivasi dan kinerja adalah suatu bagian yang saling terkait satu sama lainnya, peningkatan motivasi akan mempengaruhi peningkatan kerja dan begitu pula sebaliknya.

Berdasarkan hasil penelitian yang telah dilakukan diketahui bahwa hampir seluruh responden yang memiliki motivasi kerja baik juga memiliki kinerja yang baik yaitu sebesar 40 responden $(93,0 \%)$ dan sebagian besar responden yang memiliki motivasi kerja tidak baik dengan kinerja yang tidak baik yaitu sebesar 3 responden $(60,0 \%)$. Selain itu, berdasarkan hasil uji statistik diperoleh $P$ Value sebesar 0,010 dimana nilai tersebut kurang dari $\alpha=$ 0,05. Hal tersebut menunjukkan ada hubungan yang bermakna antara motivasi kerja dengan kinerja karyawan di Puskesmas Benda Baru Kota Tangerang Selatan.

Hasil penelitian ini sejalan dengan penelitian yang dilakukan oleh Syazhashah Putra Bahrum dan Inggrid Wahyuni Sinaga (2015) yang menjelaskan bahwa persepsi penilaian responden terhadap motivasi sangat tinggi. Selain itu, hasil penelitian ini juga sejalan dengan penelitan Inez Zaneta Hafizhah (2018) yang menjelaskan 
bahwa variabel motivasi kerja secara parsial menunjukkan pengaruh signifikan terhadap variabel kinerja pegawai. Dalam mencapai kinerja karyawan yang baik kepemimpinan harus senantiasa memberikan motivasi yang kuat pada setiap karyawan agar seluruh kinerja akan menjadi optimal

\section{KESIMPULAN}

Berdasarkan hasil analisis bivariat menggunakan uji statistik Chi Square diketahui bahwa ada hubungan yang bermakna antara kepemimpinan dengan kinerja karyawan di Puskesmas Benda Baru Kota Tangerang Selatan dengan $P$ Value sebesar 0,006 dimana nilai tersebut kurang dari $\alpha=0,05$. Selain itu, juga diketahui bahwa ada hubungan yang bermakna antara motivasi kerja dengan kinerja karyawan di Puskesmas Benda Baru Kota Tangerang Selatan dengan $P$ Value sebesar 0,010 dimana nilai tersebut kurang dari $\alpha=0,05$.

\section{DAFTAR PUSTAKA}

Anoraga, P. 2008. Psikologi Kerja. Jakarta: Rineka Cipta.

Bahrum, S.P. dan Sinaga, I.W. 2015. Pengaruh Kepemimpinan dan Motivasi Kerja terhadap Kinerja Pegawai (Studi Pada Pegawai Lembaga Dewan Kawasan
Perdagangan Bebas Pelabuhan Bebas Batam Bintan Karimun). Jurnal Politeknik Negeri Batam. Batam: Politeknik Negeri Batam.

Hafizhah, I. Z. (2018). Pengaruh Gaya Kepemimpinan dan Motivasi Kerja terhadap Kinerja Pegawai (Studi Kasus pada Fakultas Ilmu Tarbiyah dan Keguruan UIN Syarif Hidayatullah Jakarta). Jakarta: Fakultas Ekonomi dan Bisnis Universitas Islam Negeri Syarif Hidayatullah Jakarta.

Inaray, J. C., Nelwan, O. S., dan Lengkong, V. P. K. 2016. Pengaruh Kepemimpinan dan Motivasi Kerja Terhadap Kinerja Karyawan Pada PT. Amanah Finance di Manado. Jurnal Berkala Ilmiah Efisiensi, 16 (2), 458-470.

Reza, R. A. 2010. Pengaruh Gaya Kepemimpinan, Motivasi, dan Disiplin Kerja terhadap Kinerja Karyawan PT. Sinar Santosa Perkasa Banjarnegara. Skripsi. Semarang: Universitas Diponegoro.

Siagian, S. 2002. Kiat Meningkatkan Produktivitas Kerja. Jakarta: Rineka Cipta.

Siagian, S. 2009. Kiat Meningkatkan Produktivitas Kerja. Jakarta: Rineka Cipta.

Wibowo. 2011. Manajemen Kinerja. Jakarta: PT. Raja Grafindo Persada.

Wijayanti, D. W. 2012. Pengaruh Kepemimpinan dan Motivasi Kerja terhadap Kinerja Karyawan pada PT. Daya Anugerah Semesta Semarang. Skripsi. Semarang: Fakultas Ekonomi Negeri Semarang. 
Wirawan. 2009. Evaluasi Kinerja Sumber

Daya Manusia Teori Aplikasi dan

Penelitian. Jakarta: Penerbit Salemba

Empat. 
